Kente: Cape Coast Journal of Literature and the Arts

Online ISSN: 2579-0285

https://doi.org/10.47963/jla.v2i1.172

\title{
Corpus Assisted Approach To Armah's The Beautyful Ones Are Not Yet Born
}

Samuel Kwesi Nkansah 


\section{CORPUS ASSISTED APPROACH TO ARMAH'S THE BEAUTYFUL ONES}

\section{ARE NOT YET BORN}

Samuel Kwesi Nkansah

\section{University of Cape Coast, Ghana}

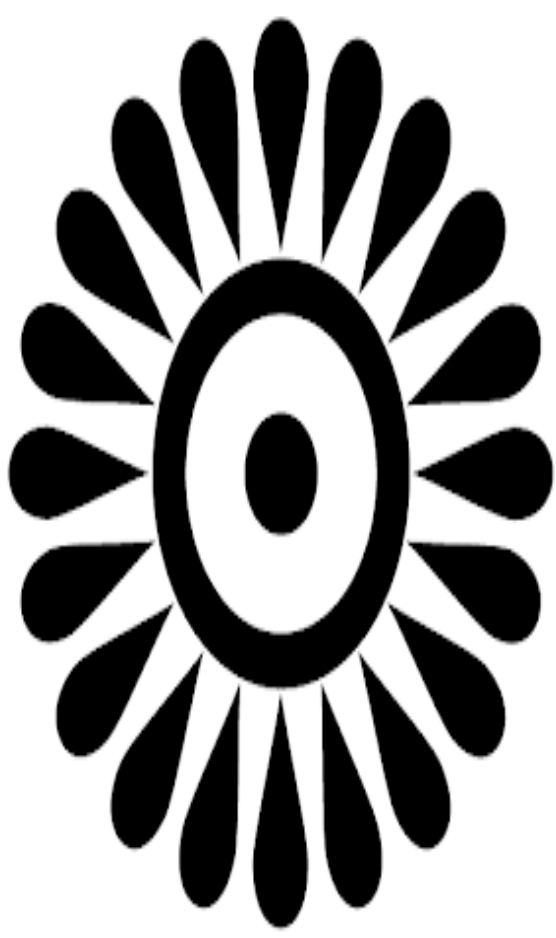

\section{ARTICLE HISTORY}

Received 11 January 2021

Accepted 19 July 2021

\section{ABSTRACT}

Armah's The Beautyful Ones are not yet Born is a novel known for its extensive portrayal of the ills and anomalies in the Ghanaian society right after independence. The majority of studies on the novel have overwhelmingly concluded that corruption is the preoccupation of the text. This view appears skewed in many respects. This paper argues that the corpus assisted approach can contribute methodologies to support objective investigation of the subject matters of the text. This study, adopting the corpus-assisted approach in a mix of numerical data and qualitative description of Armah's The Beautyful Ones are not yet Born, used frequencies of the occurrence of pejorative terms in the text to determine the dominant subject matters in the novel. The approach reveals that "rot" and "decay" are the most dominant motifs used, followed by "filth", "corruption", and "bribery". It suggests that clusters, i.e., recurrence of words, characters' association with the words, and context of use serve as textual cues in thematic exploration. The approach aids in revealing that the real intent of The Beautyful Ones Are Not Yet Born is that the total breakdown of the society rests on seemingly insignificant characters. The paper has implications for methodological approaches to thematic analysis of literary texts, particularly, the novel.

\section{KEYWORDS}

Armah; corpus assisted approach; corruption; foregrounding; subject matter

CONTACT Samuel K. Nkansah email: snkansah@ucc.edu.gh 


\section{Introduction}

The analysis and interpretation of literary texts (oral, written, and popular) have been over the years deemed subjective since diverse views on interpretation could be gleaned from the text. The quest to find a secure, scientific, and empirically proven approach is drawing in several ways in analysing and interpreting literary texts. The structuralist approach, literary stylistics, has served as a way out of this challenge. Stylistics is a domain where meaning assumes paramount importance. The term is applied not only to words, word-combinations, and sentences but also to the manner of expression; for stylistics, meaning is what is intended to be or is expressed or indicated. Simpson opines that "Stylistics is a method of textual interpretation that has language as its primary data" (3). The reason language is so important to stylisticians is because the various forms, patterns, and levels that constitute linguistic structure are an important index and foci of the function of the text. However, a crucial issue for stylistic approach to literary interpretation is the ability of a word to be polysemantic. Every word, no matter how rich it is in imagery and meaning, leaves the door open for new shades of interpretation and even for independent meanings. Stylistics (in some cases) takes for granted that a word has a potentiality of acquiring new meanings. Unlike other branches of linguistics, though stylistics provides a degree of objectivity in literary analysis, it also carries in its trail some subjectivity in the perception of meaning in words. The corpus stylistics approach, a more recent scientific approach, seems to close the gap and provide specific interpretations to specific texts in given contexts. This paper, therefore, seeks to employ the corpus assisted approach in interpreting and conducting a thematic analysis of Armah's The Beautyful Ones Are Not Yet Born and proposing an alternative approach to analysing the text - The Beautyful Ones Are Not Yet Born. Following a corpus assisted approach, this study helps in locating the linguistic uses of some lexemes in the text through quantitative means. Carter, describing the approach of analysing literary texts, asserts that this method (corpus-assisted approach) is conducted in a relatively objective way and for the optimal achievement, it should bring to bear a relatively subjective mode (67).

\section{Ayi Kwei Armah and The Beautyful Ones Are Not Yet Born}

Armah, born in 1939, used to work for Ghana Broadcasting Corporation as a scriptwriter and translator after his university education and later for a French newspaper, Jeune Afrique. He has taught in universities in Lesotho and USA (Ayachi \& Loraabi 21). His maiden novel, The Beautyful Ones Are Not Yet Born, discusses issues of corruption and rot in the newly independent country, Ghana, under Nkrumah's regime, a regime later ousted by the military. Irungu (2) states that "the writer dwells on ...corruption, poverty, prostitution and sexual immorality, drug use and alcoholism and the great inequities in income and wealth distribution".

The novel isolates an anonymous and symbolic character called the man and follows his daily activities, especially in his attempt to 'stay clean of the rot and filth' (3) in the society. The Beautyful Ones Are Not Yet Born revolves around this railway freight clerk who faces intense 
pressure, impelling him to compromise his values and patriotic convictions by joining the corruption train which seems to have everyone on board. The protagonist struggles to reconcile his personal convictions with the expectations of his loved ones and society. He faces unwarranted attack, even as he leaves home for work. On a particular occasion, a bus driver contemptuously spit at him. At the office, his patriotic traits such as dedicating himself to his assigned duties and refusing to offer or receive bribes make him an irritant to his co-workers. In the context above, he may be described as 'The beautiful'.

Unfortunately, 'the man' who tries to avoid corruption is nicknamed a "Chichidodo" (a bird that hates faeces but eats maggots that breed in faeces) by his wife. In other words, though the man is incorrupt, he does not turn down friendship from corrupt people (his colleagues at work and Koomson, a politician) and enjoys the product of corruption, an apparent meaning for the defective spelling of "beautyful" in the title of the novel. Although the man remains an uncelebrated hero throughout the story, a twist that vindicates him occurs towards the end of the story. The military takes over power from the overtly corrupt civilian government. The once distant friend of the man, Koomson, runs to the man's house and escapes through a latrine hole which he could not imagine himself using during a visit in his days as a minister. On this occasion, the potbellied politician oozes a stench that is so unbearable that his erstwhile admirer, Oyo, remarks, "He stinks ..." and confesses to the husband, "I am glad that you never become like him" (Armah 165).

The novel depicts the subject of corruption and its related thematic considerations. The subject matter draws synergies from related subjects such as poverty, social inequality, hero-worshipping, political instability, economic sabotage, solitude, and retributive justice. The author explores corruption as the main subject matter, creating disgusting images of politicians through the use of derogatory lexemes such as "constipating", "farting", "flatulence", "a group of bellies", "stupid", and "idiots". The novel demonstrates that corruption is the lifestyle of self-serving public officers such that the overthrow of a political regime is thought of as being the panacea to the perpetuation of the ills of corruption. Despite the dominance of pejorative terms in the text, the motif of corruption has attracted much scholarly attention and Koomson has been the torch bearer of the corruption in the novel. The question that arises as the title of the novel creates a gap for discussion is whether there is hope for the country.

The novel ends on a glimpse of hope as the imagery of the new car at the end evokes a sense of new beginning but this hope is tainted since the military who are protecting the new regime are seen taking bribe from the driver. This sense of continued intent is symbolised by the 'defective' spelling of "beautyful". This is a graphological foregrounding of a message. The spelling provides a possible state of mixed apprehension. Though the concluding part of the novel presents the man as not corrupt even as his wife, Oyo, confesses her admiration for the husband's resolve to remain unscathed in the overt corrupt context, the text does not resolve him of corruption. The overarching view in this paper is that the novel's defective spelling of "beautyful" points to the fact that even the seemingly incorruptible are vulnerable elements of corruption and that the most identified 
character of corruption represents an insignificant percentage. This is what this paper seeks to prove through numerical data and description.

\section{Foregrounding in stylistics}

The theory of foregrounding occupies an important place in stylistics. In all, the notions of stylistics postulated by literary scholars and linguists agree that the study of style shows not only in the use of language but also how meaning is achieved. This explains Wales' view that stylistics focuses on "the interpretation of literary texts through analysing their formal features in order to show their functional significance for the interpretation of the text" (372-373). The consistency of the features or patterns in unravelling a concealed message is key to stylistic interpretation. The emergence of a defined pattern of lexemes, phrases, clauses, and sentences which lends itself to interpretation is termed as foregrounding. Simpson perceives foregrounding as "[A] form of textual patterning which is motivated specifically for literary aesthetic purposes. Foregrounding typically involves a stylistic tweeting, either through an aspect of the text which deviates from a linguistic norm or, alternatively, where an aspect of the text is brought to the fore through repetition (or parallelism)" (50).

Foregrounding is, therefore, defined as the principle of text organization which is aimed at attracting the reader's (listener 's) attention to the pragmatically significant parts of the message (Yemets 93). In Gregoriou's view, foregrounding is a psychological effect (87) which is exploited in literary texts. One of the reasons a motif can be said to be present in a text could be that psychological effects are systematically exploited around patterned imagery, lexemes or grammatical structures. Of the approaches to analysing foregrounding, Leech singles out two quantitative and qualitative-where the techniques of the quantitative aspect such as stylistic convergence and parallelism in the stories are characterized. It is emphasized that convergence is the main technique of foregrounding (Yemets 93).

Foregrounding is realised at all levels of language use, and unusual graphical patterning, excessive lexical and pronominal repetition, unusual word choices, highly creative metaphors, parallelism, and breaches of the usual discourse structure (Dou 14). Foregrounding is basically employed to highlight specific key points to produce thematic meaning or/and prompting an emotional response, so as to yield desired artistic and contextual effects.

In this paper, I discuss the predominant use of some lexemes in projecting some issues in Armah's The Beautyful Ones Are Not Yet Born. The pervasiveness of these issues is enmeshed in foregrounding as a perspective of discussing Armah's world view on the general sense of corruption, rot, filth, and decay in the novel since his success is enshrined in the manner, he consistently uses particular lexemes as a means of foregrounding the message.

Qualitative and quantitative approaches both contribute to foregrounding. While the former relates to the deviational patterns from the language code itself, the latter comes with numerical 
computations as a means of arriving at an objective conclusion (Salomo 30). This assumption makes it possible for a corpus-assisted approach to be incorporated in the analytical methodologies.

\section{Corpus stylistics and methodology}

The research is descriptive and analytical. It is situated in the qualitative design though statistical tools are incorporated in the data collection and analysis. Specifically, this study employs the descriptive and numerical analytical method of frequencies to analyse subject/motifs in Armah's The Beautyful Ones Are Not Yet Born. Drawing a link between corpus-based data and quantitative analysis, Semino and Short (201) assert that a corpus-based work is highly quantitative in nature. However, if both quantitative and qualitative approaches are combined, they yield a higher degree of understanding of literary works or any other selected data.

According to Carter, corpus stylistic analysis is a "relatively objective methodological procedure that at its best is guided by a relatively subjective process of interpretation" (67). A corpus (plural "corpora") refers to a collection of texts stored in an electronic database. Baker, Hardie, and McEnery (49) opine that though a corpus does not project new information about language through using software packages to process data, it aids in obtaining new perspectives on the familiar. According to Wales (92), corpus stylistics is a branch of computational linguistics which was developed in the late 1960s to help investigate certain characteristics of the data like consistent use of certain words, words length, and sentence types. Corpus stylistics relies on statistical and computer-aided tools to study the frequencies of issues related to style. It is important to draw in McIntyre's attempt at shedding light on the difference between corpus stylistics and corpus linguistics. He explains corpus stylistics as simply corpus linguistics with a different object of study: the focus is literary texts (60). He demonstrates that the difference between the two is that corpus stylistics is not only borrowing tools from corpus linguistics but it makes itself unique by using qualitative tools and techniques of stylistics to analyse texts with the help of computational methods.

In fact, available research indicates that there are, to date, three possible corpus analytical approaches to text: corpus-assisted, corpus-based, and corpus-driven analyses. These categorizations are not so distinct; rather, they are means of identifying common analytical practices, which may even be used in succession, in terms of trial-and-error approaches to a target text. According to Shepherd et al. (70), corpus-assisted analyses may be carried out in order to check out a stylistician's intuition about the stylistic effects of a particular text. This way into the data neither requires the construction of specialist corpora nor does it demand particular expertise in computing or corpus analytical techniques. Adolphs (65) claims that when analysis is focused entirely on the target text in order to extrapolate information relating to that text alone, it may be seen as an intra-textual analysis. Corpus-based and corpus-driven analyses differ from corpusassisted analysis, in that they treat the target analytical text (or texts) as a corpus in its own right. The analysis is then based on the comparison between the target corpus and a reference corpus. 
Adolphs (66) calls this type of analysis inter-textual analysis. Some studies have relied on the corpus method to examine stylistic issues in literary texts. Dou, for instance, used the corpusassisted method to examine the use of parallelism in twenty short stories of Virginia Woolf (2). Stockwell and Mahlberg (378), similarly, relied on corpus methods to investigate how readers engage in mind-modelling in characterization in Charles Dickens's David Copperfield. It must be mentioned that this study employs a corpus-assisted approach to examine the recurrence of certain 'subject-laden' lexemes in Armah's The Beautyful Ones are not yet Born to unravel the major subject matter and how they aggregate to magnify the major thematic concerns in the aforementioned text.

Data was collected by manually counting and writing down the number of times these motifs are used in The Beautyful Ones Are Not Yet Born: rot, corruption, bribery, filth, and decay. A frequency distribution table and bar chart are used to summarize the frequencies of occurrences of the selected motifs in the fifteen chapters. This study follows Mahlberg and McIntyre's methodology as cited by Adil Jaafar in "Corpus Stylistic Analysis of Thomas Harris' The Silence of the Lambs". The model focuses on one single literary text. They explain that studying one text may be considered as a "small sample of data" but the text is still regarded as part of a corpus (206). In their article, they show how a word like "table" refers to the fictional world of the novel, Casino Royale, since this word has a tangible meaning and it has a reference to one of the concrete objects that can be found in a place like a casino. In other words, it has the main function of being a 'thematic signal' keyword. It is in this vein that this paper uses corpus-assisted approach to determine the thematic direction of the narrative in the number of times the lexemes such as rot, corruption, bribery, filth, and decay have been used in the novel. These lexemes are gathered through an intensive scanning and close reading of Armah's The Beautyful Ones Are Not Yet Born. To ensure objectivity, no word is left out; the text was read over and over for a period of three months.

\section{Analysis and discussion}

The study seeks to analyse Ayi Kwei Armah's use of rot, bribery, filth, decay, and corruption to determine the prominence given to each motif based on a word count. Table 1 and Figure 1 present the frequency of occurrence of the motifs in the text:

Table 1: Ayi Kwei Armah's Use of Rot, Filth, Decay, Bribery and Corruption

\begin{tabular}{|c|c|c|c|c|c|c|}
\hline & \multicolumn{2}{|l|}{ Corruption } & \multicolumn{2}{|c|}{ Decomposition } & \multicolumn{2}{|c|}{ Filthiness } \\
\hline Subject & Corruption/ & Bribery & Rot/ & Decay & Filth/ & Dirt \\
\hline Word count & 4 & 4 & 29 & 14 & 4 & 8 \\
\hline Total count & 8 & & & & 12 & \\
\hline
\end{tabular}




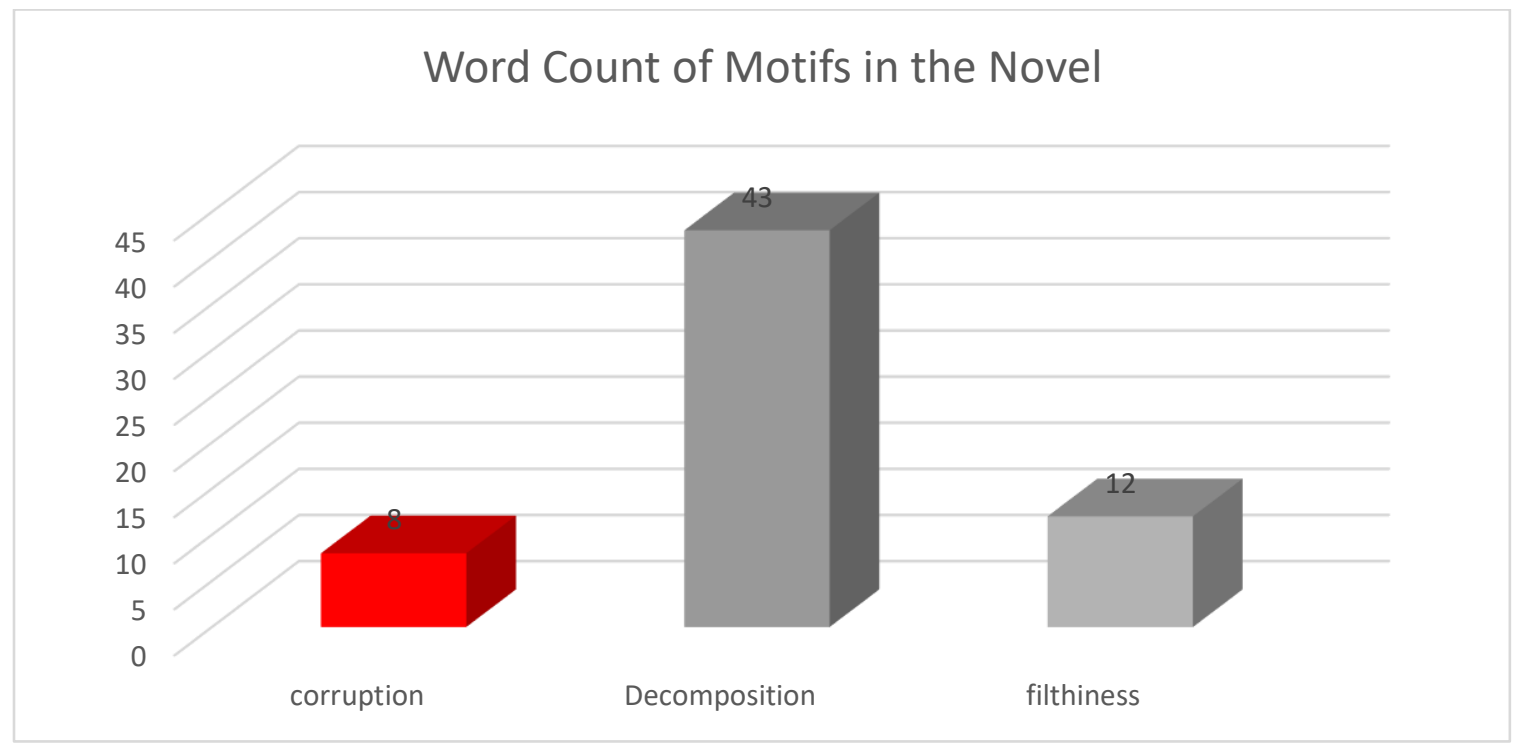

Figure 1: Ayi Kwei Armah's Use of Corruption (corruption and bribery), Decomposition (rot and decay), and Filthiness (filth and dirt)

It is realized that among corruption, decomposition, and filth, there is the prevalence of decomposition and degeneration than corruption, as indicated by the most frequent occurrence of the terms rot and decay which occur twenty-nine (43) representing 66\%, filth and dirt fourteen (14) times representing $21.5 \%$ and bribery and corruption eight (8) times representing $12 \%$ in the novel respectively. The data suggest that rot and decay, which the researcher labels as 'decomposition', is a dominant concern that seeks to drown the nation in the novel. The extract below affirms this point:

R1: It was a most unexpected smell for something so new to have: it was a very old smell, very strong, and so very rotten that the stench itself of it came with a curious, satisfying pleasure (Armah 3).

The description of the new Ghana cedi as being ironically rotten is symbolic of Ghana, right after her independence. Ayi Kwei Armah is puzzled as to why a 'new' country which has fought tirelessly to be free from colonial domination will still be stinking unimaginably with poverty, abuse of power by leaders, and neglect of duties by her citizens. A similar conclusion can be drawn from the extract on decay below:

D3: Sometimes it is understandable that people spit so much, when all around decaying things push inward and mix all the body's juices with the taste of rot (Armah 40).

Ayi Kwei Armah associates the discomfort of the citizenry to the material decay in the society. The author intimates the extent of decay in the society. Almost everything is decaying in the 
country and the citizens are the ones affected, as they feel the decay deeply in their throat. Further instances of rot and decay have been presented in Table 2:

Table 2: Further instances of rot and decay Armah's The Beautyful Ones are not yet Born

Code Instances of Decomposition (Rot/Decay) Reference Page

R1 It was a very old smell, very strong, and so very rotten that the 3 stench itself of it came with a curious, satisfying pleasure

R2 His nostrils lost the smell of the cedi's marvellous rottenness

R3 Your mother's rotten cunt

D1 All rounded out and smoothed, consumed by some soft, gentle process of decay

R4 It was in the nature of the wood to rot

R5 The polish, it was supposed, would catch the rot

R6 It was the rot which imprisoned everything in its effortless embrace

R7 I cut my timber a long time ago and it is still waiting in the forest.

Half of it will be rotten soon

R8 You think my timber should rot in the forest? 29

R9 I say my timber is rotting in the forest 31

D2 Old water that has stopped flowing and confused itself with 40 decaying oil from broken-down boilers

D3 Sometimes it is understandable that people spit so much, when all 40 around decaying things push inward

R10 ...dust and perpetual mud covered over with crushed tomatoes and $\quad 40$ rotten vegetables

R11 when all around decaying things push inward and mix all the 40 body's juices with the taste of rot

R12 There is only the stale soapsuds merging in grainy rotten dirt from everybody's scum... 
R13 Some of that kind of cleanness has more rottenness in it than the 44 slime at the bottom of a garbage dump

D4 ...there was too much of the unnatural in any man who imagines he could escape the inevitable decay of life

D5 ...since all around him showed him the horrible threat of decay $\quad 48$

D6 ..his body inside had undergone far more decay than any living 48 body

R14 ....and so what did the dead rot inside the friend not have to do with his fear

D7 ...what was decaying outside of himself?

The study revealed that Armah's use of rot and decay as descriptive terms cuts across animate and inanimate objects. In Table 2, the banister (R4), timber (R9), and vegetables (R10) are all victims of the decomposition that had befallen the country. Similarly, in R11 and R14, rot is used to indicate decomposition in humans. At this point, it is obvious that rot and decay signify decomposition, breakdown, and deterioration.

Contrary to perceptions in the literature that corruption is the overriding motif used to describe the practices of characters, the study reveals that Armah's use of rot goes beyond describing the 'perishable' (as in R1, 3 \& 10) to include deviant attitudes. This is exemplified in the extract below:

And everybody knew the chances of finding a way that was not rotten from the beginning were always ridiculously small. Many have found it worthwhile to try the rotten ways, and in truth there was no one living who had the strength to open his mouth to utter blame against them. Many had tried the rotten ways and found them filled with the sweetness of life (Armah 145).

The ways taken by the likes of Koomson, Amankwah, and all the fat men implicated in the novel are termed as rotten and not just corrupt. Armah seems to suggest corruption is not a term strong enough to describe the anomalies of the African leaders and will rather opt for a more degrading term as rot. This is a possible explanation for the predominant use of the term (29 times representing 44.6\%) in the novel, The Beautyful Ones Are Not Yet Born.

The summing essence of the numerical dominance of the rot and decay broadens both the agents and perpetrators of rot and decay and thereby the general implication it has on the main subject matter of the novel. Two assertions come up from this discussion. One, the overwhelming presence of decadence suggest that Armah deems it relevant to spread and share the burden of responsibility 
among all by assigning both significant and insignificant roles to diverse characters in the novel. Two, since rot and decay are common elements of decomposition, most researchers gloss over them and their rippling literary implications but giving scholarly premium to major characters in the novel.

On corruption, the major and only political character in the narrative is Koomson, who is associated with the subject matter of corruption which appears just four times in the narrative. The other synonyms of corruption, such as "bribery" appearing four times, are related to characters other than Koomson. Though the two subjects subsume under corruption (representing less than $12.6 \%$ of the dominant controlling subject matter/motif), it is evident that Koomson is not the only character who perpetuates corrupt acts in the text; corruption represents $6.3 \%$. On the other hand, rot, decay, filth, and dirt appear $29,14,4$, and 8 times respectively, representing $87.40 \%$ of the total dominant subject matter/motif in the narrative.

In numerical strength, there are more characters who are associated with bribery and corruption as a subject matter/motif than Koomson. There is the bus conductor who attempts to cheat passengers on the bus, feels threatened at the gazing face of the man and when he realises that the man is not looking at him, he is rather infuriated and insults the man. At the beginning of the story, the driver of the old bus gives the police bribe, apparently, to allow him drive on since his bus is not in good shape. The situation becomes alarming when at the end of the story, the driver of the new bus also bribes the police for no reason. This singular act creates a view that corruption is an endemic phenomenon in the society and its pervasiveness embraces all, not just Koomson and his political allies. Amankwaa sees bribery as a normal way of influencing the workers at the railway office to have his timber cart out of the forest (Armah 29-30). When the man refuses to take the two tencedi notes, Amankwaa interprets it as wickedness on the part of the man. Amankwaa manages to get another railway clerk who accepts the bribe and Amankwaa sees him as a friend. In this, Oyo and her mother scorn the man for refusing to accept the bribe. The experience of the messenger who won a hundred cedis in lotto comes in to endorse the endemic of bribery and corruption in the society. Though unapproved, he wishes that a big man at the National Lotteries takes some of the win and helps him get the rest (Armah 19). When the messenger is cautioned that he will be corrupting public official, "he smiles and says, "this Ghana"”.

Characters who are overtly associated with corruption in the novel contribute to the $12.6 \%$ of the detestable acts exposed in the text, thus, bribery and corruption. The characters identified are all engaged in projecting one subject matter/motif, bribery and corruption. Thus, focusing on Koomson as a symbolic figure of corruption simply because he occupies a political space and thus representative of all unmentioned political actors in the broader politics of the narrative skews the subject and its agent. 


\section{Literary and methodological implications}

The discussion and analysis reveal that there are more word/motifs that demonstrate higher frequencies than the much-touted subject matter of the narrative: corruption.

A more objective analysis of the subject matters in this narrative will focus on the higher numerical representation, the $87.40 \%$. Literary texts are considered as presenting the macro society on a micro scale. The assumption, then, is that the characters-major, minor, and supporting onesplay micro roles to reflect the macro characters. The more representative, the wider the scope of coverage. The $87.40 \%$ of the character roles played by characters other than Koomson broadens the subject matter from just corruption to symbolic entities whose roles are metaphorical extension of phases of corruption such as social, verbal, moral, financial, and even physical corruption. Another literary implication is that the other derogatory subjects/motifs are contextual synonyms of corruption but they define the nature and level of corruption according to the characters involved. This provides a wider net within which literary analysts can pack possible manifestations of corruption as a dominant subject/motif in the narrative. Again, this implication provides a basis for considering the motifs as extended metaphors of corruption and its broader involvement of the macro society and its elements.

Corpus assisted approach as a methodological tool imbues stylisticians with scientific evidence of literary analysis. The statistical data from the novel give numerical justifications to assumptions and ultimate interpretations of the subjects/motifs. Thus, using statistical data, the analysis becomes more objective and allows us to draw broader conclusions. The approach also comes with a degree of ease with which stylistic analysis is carried out. The process of extracting data from a literary text is simpler than extracting themes that are usually shrouded in literary terminologies. Employing numerical strength as a literary tool in determining the dominant subject /motif of literary text takes away subjectivity and opens up literary analysis to all manner of people, both numeracy oriented and 'haters of numbers.'

\section{Conclusion}

The discussion has brought out a number of confluences between methodologies and literary analysis. Armah's The Beautyful Ones are not yet Born, a novel known for its extensive treatment of corruption as a major ill, has others more plaguing ills that are glossed over. This paper, through a corpus assisted approach, identified the frequencies of "rot", "corruption", "bribery", "decay", and "filth", and established that "rot", "decay", and "filth" are more pervasive subjects/motifs in the novel. It is also evident that "corruption" as a subject matter/motif realises full literary import only in association to the others. The examination has exemplified that clusters, i.e. recurrence of words, characters' association with the words, and context of use serve as textual cues in thematic exploration. The simplicity of the approach makes the analysis easier and manageable by both numerically-oriented scholars or pure literary analyst to undertake thematic analysis of a text. 


\section{AUTHORIAL BIO}

Samuel Kwesi Nkansah is a Senior Lecturer in the Department of English, University of Cape Coast. He holds PhD in Literary Stylistics. His research interest includes Literary Stylistics, Emergent Music genre, Humour in Literature, African Literature (Oral and Written). Samuel Kwesi Nkansah has presented papers at both local and international conferences. He has also published in both local and international journals.

\section{DECLARATION}

I declare that I had full access to all study data, take fully responsibility for the accuracy of the data analysis, and have authority over manuscript preparation and decisions to submit the manuscript for publication

\section{ACKNOWLEDGEMENT}

I acknowledge the reviewing editors whose critical comments fine-tuned the paper. I particularly appreciate the contributions of my postgraduate students, Mr. Rexford Gyasi Boateng and Ebenezer Agbaglo, for contributing in diverse ways to make this project a reality.

ORCID NUMBER: https://orcid.org/0000-0002-0181-4589

\section{Cited Works}

Adolphs, Svenja. Introducing Electronic Text Analysis. London, Routledge, 2006. Armah, Ayi Kwei. The Beautiful Ones Are Not Yet Born. Harlow, Heinemann, 1968.

Ayachi, Meriem and Romaissa Lorabi. Psychology of the Oppressed in Ayi Kwei Amah's The Beautyful Ones Are Not Yet Born. University of Mohamed Boudiaf-M'Sila, Algeria, 2019.

Baker, Paul., Andrew Hardie, and Tony McEnery. Glossary of Corpus Linguistics. Edinburgh: Edinburgh University Press, 2006.

Carter, Ronald. "Methodologies for Stylistic Analysis: Practices and Pedagogies." Language and Style. Ed. B. Busse and D. McIntyre. Basingstoke: Palgrave, 2010, 55-68

Dou, Abdelbasset. A Corpus-Assisted Stylistic Analysis of Parallelism in Virginia Woolf 's Short Fiction -The Case of Twenty Short Stories. Algeria: Ministry of Higher Education and Scientific Research Faculty of Foreign Languages Department of English, 2018. 
Etikan, Ilker, Sulaiman Abubakar Musa, and Rukayya Sunusi Alkassim. "Comparison of Convenience Sampling and Purposive Sampling." American Journal of Theoretical and Applied Statistics 5.1 (2016): 1-4.

Gregoriou, Christiana. 'The Linguistic Levels of Foregrounding in Stylistics'. Michael Burke (ed) In The Routledge Handbook of Stylistics. New York, Routledge, 2014, 87-100.

Irungu, Eric. "Analysis of the Political Themes in Ayi Kwei Armah's Novel The Beautyful Ones Are Not Yet Born". Academia Online, 2014. URL: https://www.academia.edu/6830121/An_Analysis_of_the_Political_Themes_in_Ayi_Kw ei_Armahs_Novel_The_Beautyful_Ones_Are_Not_Yet_Born_

Lambert, Vickie A., and Clinton E. Lambert. "Qualitative Descriptive Research: An Acceptable Design." Pacific Rim International Journal of Nursing Research 16.4 (2012): 255-256.

Leech, Geoffrey and Mick Short. Style in Fiction. London: Longman, 1981.

McIntyre, Dan. "Corpora and Literature". Wiley Blackwell Encyclopedia of Applied Linguistics. In C.A: Chapelle, ed. Oxford, Wiley Blackwell, 2012.

Salomo, Fikameni. A Discourse Analysis of Metropolitan and Sanlam Namibia's English Print Advertisements in the Namibian Newspapers: A Comparative Study. (Unpublished MA Thesis). University of Namibia, Windhoek, 2015.

Semino, Elena, and Mick Short. Corpus Stylistics: Speech, Writing and Thought Presentation in a Corpus of English Writing. Routledge, 2004.

Shepherd, Tania MG and Tony Berber Sardinha. "A Rough Guide to Doing Corpus Stylistics." Matraga-Revista do Programa de Pós-Graduação em Letras da UERJ 20.32 (2013).

Simpson, Paul. Stylistics: A Resource Book for Students. London: Routledge, 2004.

Stockwell, Peter and Michaela Mahlberg. "Mind-modelling with Corpus Stylistics in David Copperfield." Language and Literature 24.2 (2015): 129-147.

Wales, Katie. A Dictionary of Stylistics, $3^{\text {rd }}$ Ed. London: Routledge, 2011.

Yemets, Alexander. "Types and Functions of Foregrounding in the Contemporary Flash Fiction Stories." SKASE Journal of Theoretical Linguistics, 16.4, 2019, 93 Gale LiteratureResourceCenter, link.gale.com/apps/doc/A613272783/LitRC?u=anon 32274a8 $5 \&$ sid=googleScholar\&xid=33635401. Accessed 29 June 2021. 